\title{
Application of biochemical fingerprinting to the investigation of clonal groups of Salmonella of serotype Havana
}

\author{
M. KATOULI, I. KÜHN*, A. BRAUNER†, A. A. FARHOUDI-MOGHADDAM $\ddagger$ and R. MÖLLBY
}

Department of Bacteriology, Karolinska Institute, Box 60400, S-104 01 Stockholm, "The National Bacteriological Laboratory, S-105 21 Stockholm, +Department of Microbiology, Karolinska Hospital and Stockholm County Council Central Microbiological Laboratory, Stockholm, Sweden and $\ddagger$ The Microbiology Department, Pasteur Institute of Iran, Tehran 13164, Iran

\begin{abstract}
Summary. A computerised typing method based on biochemical fingerprinting was used to investigate biochemical phenotypes (BPTs) among 70 strains of Salmonella of serotype Havana isolated from human cases of gastroenteritis in Iran and other parts of the world. A total of 16 BPTs comprising five common and 11 single phenotypes was identified. The most frequently found BPT contained 24 isolates from Iran and nine from other countries. Three common BPTs with two, seven and 15 isolates were found among Iranian strains only and one common BPT with two isolates was found among non-Iranian strains only. Antibioticresistance patterns and virulence properties of strains from these common BPTs suggested that they might be unique clones. Forty-two Iranian isolates shared multi-resistance to between three and seven antibiotics. In contrast, none of the isolates from other countries was resistant to antibiotics. Furthermore, 43 Iranian isolates showed mannose-resistant adhesion to HeLa cells and 24 of them possessed an aerobactin-mediated iron-uptake system, whereas none of the isolates from other countries possessed any of these virulence properties. These findings suggest that four unique clones of Salmonella Havana with different BPTs and virulence properties are common in Iran; two particular clones were responsible for a majority of Havana infections there. However, the most prevalent BPT found among Iranian strains was also common in strains from other countries. It is concluded that biochemical fingerprinting, as used in this study, is a reliable method for identifying clonal groups of Havana strains. The method is reproducible, easy to perform and can be used alone, or in combination with other typing methods, in epidemiological studies of serotype Havana.
\end{abstract}

\section{Introduction}

Salmonella enterica subsp. enterica serotype Havana was first reported by Corbelo and Martinez-Cruz ${ }^{1}$ in an outbreak of meningitis in a Cuban nursery in which there were at least 21 deaths. Although it is generally considered to be a salmonella serotype rarely associated with human disease, an increase in the frequency of its isolation from human sources has been observed in recent years. ${ }^{2.3}$ Furthermore, it is a serotype commonly associated with poultry ${ }^{4}$ and their feed supplements ${ }^{5.7}$ in different countries. We have shown previously that, after Typhimurium, Havana is the second most prevalent salmonella serotype associated with human gastroenteritis in Iran, accounting for $31 \%$ of all salmonellae isolated there over a 3 -year period. ${ }^{8}$ Whereas many epidemiological markers such as phage typing, ${ }^{9}$ biotyping, ${ }^{10,11}$ and plasmid-profile analysis ${ }^{12,13}$ have been used to identify clones, or to trace sources of infections ${ }^{14-16}$ by different serotypes of Salmonella, the lack of any method to differentiate among strains of Havana is evident. No phage-typing scheme is currently available, and plasmid-profile analysis or antimicrobial-susceptibility testing are not helpful if the organism does not contain plasmids or is sensitive to antibiotics. It has been postulated that many sporadic cases of infection by Havana, that may indeed be part of unrecognised outbreaks, escape detection because of the unavailability of such markers. $^{2}$

A computerised typing method based on biochemical fingerprinting (the PhP system) has been developed $^{17,18}$ that measures quantitatively the kinetics of several biochemical reactions of bacteria grown in microtitration plates and yields for each strain a biochemical fingerprint consisting of several kinds of quantitative data. A personal computer can be used to calculate the similarities among tested strains by 
numerical analysis. The strains are divided into biochemical phenotypes (BPTs).

In the present study we used a set of specifically selected substrates for discrimination of Havana strains and used the system to investigate biochemical phenotypes of strains isolated from cases of human gastroenteritis in Iran and other countries. We also evaluated the patterns of antibiotic resistance and the presence of some putative virulence characters among these strains.

\section{Materials and methods}

\section{Bacterial strains}

Of 70 strains of Havana studied, 55 were isolated between Feb. 1986 and March 1987 from children $<5$ years of age admitted to children's hospitals in Tehran, Iran, and who had severe gastroenteritis; another 15 strains had been isolated in different countries between 1988 and 1990. The non-Iranian strains, kindly provided by $\mathrm{Dr} \mathrm{R}$. Wollin, the National Bacteriological Laboratory, Stockholm, Sweden, had been isolated from cases of human gastroenteritis (11), beef (2), horse meat (1) and mung beans (1) in the following countries: Australia (4), Spain (3), Thailand (2), Sweden (2) and Argentina, Ethiopia and Panama ( 1 each); the source of one strain was unknown. All strains were stored in deep agar at $4^{\circ} \mathrm{C}$ until tested for biochemical phenotypes and virulence properties.

\section{Antimicrobial-susceptibility testing}

Identification of Iranian isolates and their pattern of antimicrobial drug-resistance against the antibiotics most commonly used in Iran have been described previously. ${ }^{8}$ The antimicrobial agents were: chloramphenicol (C); tetracycline (T); ampicillin (A); sulphamethoxazole-trimethoprim (SxT); kanamycin (K); streptomycin (S); cephalothin (Cf); nalidixic acid $(\mathrm{Nx})$; and furoxone (F). Susceptibility of the nonIranian isolates to that same series of agents was determined by a standard disk-diffusion method. ${ }^{19}$ Resistance of strains to each antibiotic was number coded as follows: $(C=200) ;(T=100) ;(A=50)$; $(\mathrm{SxT}=20) ; \quad(\mathrm{K}=10) ; \quad(\mathrm{S}=5) ; \quad(\mathrm{Cf}=2) ; \quad$ and $(\mathrm{Nx}=1)$; antibiotic sensitivity was coded as 0 . The sum of the values of the agents to which strains were resistant was used to indicate the antimicrobial resistance pattern (resistotype) of strains, giving each a unique resistotype (RT) pattern; for example, an RT of 387 indicated that the strain was resistant to C, T, A, SxT, K, S and Cf whereas an RT of 0 indicated that the strain was sensitive to all antibiotics tested.

\section{Biochemical fingerprinting}

The principle of the PhP system used in this study and the preparation of substrates in microtitration plates have been described previously. ${ }^{17} \mathrm{~A}$ set of 18 substrates, chosen specifically to give a high degree of discrimination among Havana strains, comprised: L-arabinose, maltose, melibiose, inositol, sorbitol, dulcitol, deoxyribose, rhamnose, L-fucose, tagatose, melibionate, galactonic-lactone, citrate, fumarate, malonate, pyruvate, L-tartrate and ornithine.

A single colony of each strain grown on MacConkey agar was subcultured to nutrient agar and grown at $37^{\circ} \mathrm{C}$ overnight. A loopful of this culture was suspended in $8 \mathrm{ml}$ of sterile Proteose Peptone (Difco) $0.1 \% \mathrm{w} / \mathrm{v}$ containing bromothymol blue $0.01 \% \mathrm{w} / \mathrm{v}$, $150-\mu \mathrm{l}$ volumes of suspensions were inoculated into 18 wells in pre-prepared microtitration plates with the above 18 substrates (final substrate concentration $3.75 \mathrm{~g} / \mathrm{L}$ ). For proper rehydration of the substrates, plates were held at $4^{\circ} \mathrm{C}$ overnight, and incubated at $37^{\circ} \mathrm{C}$ next morning. The $A_{620}$ of each reaction was measured after $4,7,24$ and $48 \mathrm{~h}$ by means of a Microplate Reader (Titertek Multiscan, Flow Laboratories). The absorbance values were automatically transferred to a personal computer (Victor-V286C) and multiplied by 10 , yielding scores ranging from 0 to 30 for each reaction, where low values indicate acidic (yellow) reactions and high values alkaline (deep blue) reactions. After the final reading, the mean value of four readings was calculated giving 18 different numbers ranging from 0 to 30 for each strain (the biochemical fingerprint).

The similarities between all tested strains were calculated as correlation coefficients (r) as described before, ${ }^{17}$ and were clustered according to the unweighted pair group method with arithmetic averages (UPGMA) ${ }^{20}$ yielding a dendrogram. Data-handling, including optical readings, was performed with the $\mathrm{PhP}$ software (BioSys, inova, Stockholm).

An identity level of 0.980 was set, based on the reproducibility of the system (i.e., mean $\mathbf{r}-2 \mathrm{SD}$ ) after testing 12 Havana isolates in duplicate. Thus, strains with $\mathbf{r}$ values $>0.980$ were assigned to the same biochemical phenotype (BPT); BPTs containing $>1$ isolate were called common BPTs, those with only one isolate single BPTs.

\section{Tests for virulence factors}

Adhesion. The presence of adhesive properties of bacteria was demonstrated by testing their ability to colonise HeLa cells by the method originally described by Cravioto et al. ${ }^{21} \mathrm{HeLa}$ cells were grown in chambers $\left(10 \mathrm{~mm}^{2}\right)$ on microscope slides (Chamber-slide, Lab Tek, Nunc Inc., Naproville) containing $0.3 \mathrm{ml}$ of Medium 199 with Earle's salts, supplemented with penicillin $100 \mathrm{U} / \mathrm{ml}$, streptomycin $100 \mu \mathrm{g} / \mathrm{ml}, 2 \mathrm{mM}-$ glutamine and fetal bovine serum $10 \% \mathrm{v} / \mathrm{v}$. Culture medium was replaced with the same medium containing D-mannose $1 \% \mathrm{w} / \mathrm{v}$ before inoculation of bacterial cultures. Bacterial suspensions $(20 \mu \mathrm{l})$ grown in L-broth (Difco) at $37^{\circ} \mathrm{C}$ overnight were added to each well and slides were incubated for $3 \mathrm{~h}$ at $37^{\circ} \mathrm{C}$ in an atmosphere of $\mathrm{CO}_{2} 5 \% \mathrm{v} / \mathrm{v}$ in air. Wells were 
washed three times with Hanks's Balanced Salts Solution, fixed with ethanol $70 \%$ and stained with a 1 in 10 dilution of Giemsa stain for $20 \mathrm{~min}$. After rinsing with phosphate-buffered saline, $\mathrm{pH} 7.2$ (PBS), chambers were removed, slides were dried in air and observed by light microscopy. Attachment of bacteria to HeLa cells as a cluster or microcolony was designated localised $(L)$ adhesion, whereas attachment over the entire surface of the cells was designated diffuse (D) adhesion. ${ }^{22}$

Aerobactin production. Agar plates were prepared from minimal medium ${ }^{23}$ supplemented with Casamino Acids (Difco) $5 \mathrm{~g}$, glucose $2 \mathrm{~g}$, thiamine $50 \mathrm{mg}$ and tryptophane $20 \mathrm{mg} / \mathrm{L}$. After sterilisation, $160 \mu \mathrm{M}$ 2,2'-dipyridyl dissolved in methanol was added. Agar plates were covered with a suspension of an aerobactin-requiring Escherichia coli strain LG 1522 (kindly supplied by Dr J. B. Neilands, University of California, Berkeley, CA, USA). Test strains were applied to agar plates and incubated overnight at $37^{\circ} \mathrm{C}$. Growth around the inoculum indicated aerobactin production by that strain.

Haemolysin production. Defibrinated sheep blood, washed three times in $0.01 \mathrm{M}$ Tris-hydrochloride buffer pH 7.5 containing $0.135 \mathrm{M} \mathrm{NaCl}$, was added to Blood Agar Base No. 2 (Oxoid) at a final concentration of $5 \% \mathrm{v} / \mathrm{v}$. Plates were examined for haemolysis after overnight incubation at $37^{\circ} \mathrm{C}$.

\section{Results}

Sixteen BPTs, five common and 11 single, were identified (table I). The most frequently encountered BPT (B1) comprised 24 Iranian isolates and nine from other countries-Australia and Spain (three each), Ethiopia, Panama and Sweden (one each). At a similarity level of 0.80 , all strains were grouped in five phenotypic clusters (fig. 1). Cluster A, containing Iranian isolates only, consisted of two common BPTs $\mathrm{A} 1$ and A4 (with seven and two isolates, respectively) and the single BPTs A2, A3 and A5. The major difference between the common BPTs A1 and A4 was the ability of the former group to utilise tagatose $\left(\operatorname{tag}^{+}\right)$.

Cluster B, accounting for $77 \%$ of the isolates, contained both Iranian (40) and non-Iranian (14) strains. Of these, 24 Iranian and nine non-Iranian isolates belonged to BPT B1 and 15 Iranian isolates belonged to BPT B6 which differed from B1 in its inability to ferment maltose $\left(\mathrm{mal}^{-}\right)$. BPT B7 in that same cluster contained two isolates from Thailand that differed from those of BPT B1 in their inability to ferment inositol (ino ${ }^{-}$) (fig. 1). Furthermore, strains of BPT B7 also had a slower rate of sorbitol utilisation than those of BPT B1. Unlike strains in cluster A, strains within cluster B lacked the ability to ferment galactonic-lactone ( galn $\left.^{-}\right)$.

Strains of cluster C (2), like those of cluster A, were galn ${ }^{+}$but failed to ferment melibionate $\left(\mathrm{melb}^{-}\right)$and
Table I. Distribution of biochemical phenotypes and resistotypes among strains of Salmonella of serotype Havana

\begin{tabular}{cccc}
\hline $\begin{array}{c}\text { Biochemical } \\
\text { phenotype (BPT) }\end{array}$ & $\begin{array}{c}\text { Number of } \\
\text { strains }\end{array}$ & $\begin{array}{c}\text { Resistotype } \\
\text { (RT) }\end{array}$ & $\begin{array}{c}\text { Number of } \\
\text { strains }\end{array}$ \\
\hline A1 & 7 & 387 & 12 \\
A2 & 1 & 385 & 14 \\
A3 & 1 & 380 & 3 \\
A4 & 2 & 377 & 1 \\
A5 & 1 & 375 & 1 \\
B1 & $33\left(9^{*}\right)$ & 367 & 2 \\
B2 & $1^{*}$ & 365 & 7 \\
B3 & $1^{*}$ & 357 & 1 \\
B4 & 1 & 355 & 3 \\
B5 & $1^{*}$ & 265 & 1 \\
B6 & 15 & 255 & 1 \\
B7 & $2^{*}$ & 185 & 1 \\
C1 & 1 & 167 & 2 \\
C2 & 1 & 65 & 3 \\
D1 & 1 & 20 & 1 \\
E1 & $1^{*}$ & 0 & $17\left(15^{*}\right)$ \\
\hline
\end{tabular}

* Of 70 strains tested, 15 were isolated in countries other than Iran. For RT, see Materials and methods.

melibiose (mels ${ }^{-}$) (fig. 1). The strains of single BPTs D1 (from Iran) and E1 (from Australia) differed in several properties from each other and from the other strains.

A total of 16 different resistotypes (RTs) was identified among the 70 Havana strains studied (table I). Fifty-two Iranian strains were multi-resistant to between three and seven antibiotics. In contrast, none of the strains from other countries showed resistance to the antibiotics used in this study. The major RT was 385 (14 strains) followed by RTs 387 (12 strains) and 365 (seven strains) (table I) which differed from RT 385 by resistance to $\mathrm{Cf}$ and sensitivity to SxT, respectively. Together, these three RTs accounted for $60 \%$ of Iranian isolates and $82 \%$ (27 strains) of them belonged to the common BPTs B1 (14 strains) and B6 (13 strains) (table II). The other less common RTs were few in number and were distributed among different BPTs. Biochemical fingerprinting together with resistotyping yielded 31 "clonal" groups, consisting of 13 common and 18 single phenotypes (table II).

Forty-three $(78 \%)$ Iranian isolates showed mannose-resistant adhesion (MRA) to HeLa cells in patterns that were localised (L, 39 strains), diffuse (D, 2 strains) or both of these (L/D, two strains) (table III). In contrast, none of the strains from other countries was adherent in this cell-culture assay. Thirty-one $(72 \%)$ adherent strains (L pattern) belonged to common BPTs B1 (18 strains) and B6 (13 strains) (table III). None of the strains was haemolytic but aerobactin was produced by 24 Iranian isolates belonging to common BPTs B1 (nine strains) and B6 (15 strains).

Biochemical fingerprinting together with resistotyping and production of virulence properties divided the strains into 39 "clonal" groups (same BPT, RT 
Correlation coefficient

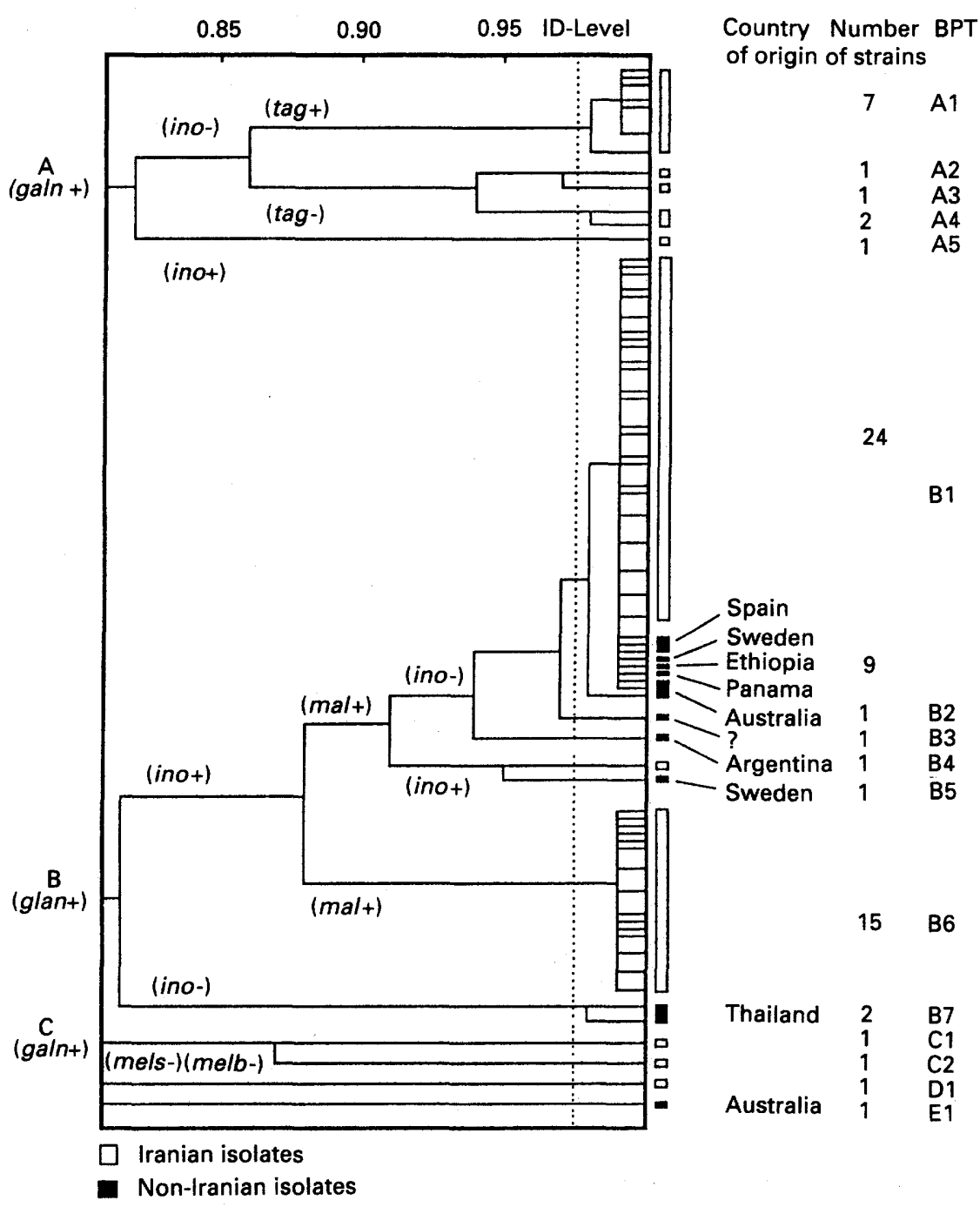

Fig. 1. Dendrogram for 70 strains of Salmonella serotype Havana, isolated in Iran (55) and other countries* (15). ID-level indicates the chosen identify level $(\mathbf{r}=0.980)$ for strains assigned to the same BPT ; ? = unknown source; + or - signs indicate the ability or inability of the strains to utilise galactonic-lactone ( galn), inositol (ino), tagatose (tag), maltose (mal), melibiose (mels), melibionate (melb).

and virulence properties) consisting of 15 common and 24 single phenotypes (fig. 2). Thirty-three phenotypes (13 common and 20 single) were found among Iranian isolates and six phenotypes (two common and four single) among strains from other countries (fig. 2).

\section{Discussion}

For subtyping strains of different serotypes of Salmonella, both phenotypic and genotypic methods have been used, ${ }^{15,16,24-25}$ some of which, whilst providing crucial epidemiological data useful for identifying outbreak strains and tracing sources of infection, are either complex or are useful only when the strain has unusual characteristics. Our biochemical-fingerprinting method revealed four different clones with different BPTs and virulence properties that were common in Iran; two, and probably related, clones were in particular responsible for the majority of Havana infections in Iran. It has been postulated that in any country where conditions are favourable for the establishment of salmonellae in man and animals, relatively few clones are responsible for the majority of infections. ${ }^{26}$

Biochemical phenotypes among salmonellae ${ }^{10,11}$ and other bacteria ${ }^{27,28}$ vary widely. The finding that nine non-Iranian isolates showed identity with 24 Iranian isolates (BPT B1) implies that this BPT is common among Havana strains in several parts of the world. However, Iranian strains were not only multiresistant but also possessed different virulence properties. Many virulence genes are coded by plasmids which are readily lost or acquired by bacteria. Again, antimicrobial-resistance traits encoded in gram-negative bacteria by $R$-plasmids ${ }^{29}$ may be mobilised to other strains if the resistant strains also carry resistance transfer factor (RTF). We previously showed that the frequency of RTF among Havana strains isolated in Iran varied between 24 and $75 \%$ with regard to the 
antibiotics used in this study. ${ }^{8}$ In contrast, biochemical reactions are generally determined by chromosomal genes and are relatively stable. We have previously evaluated the stability of biochemical reactions of $E$. coli upon storage or repeated subculturing and showed that, although some variations may occur in certain tests, the overall biochemical phenotypes of the strains remained constant. ${ }^{30}$

The ability to utilise galactonic-lactone as a sole

Table II. Strains of Salmonella of serotype Havana grouped by biochemical phenotype (BPT) and resistotype (RT)

\begin{tabular}{|c|c|c|}
\hline \multicolumn{3}{|c|}{ Phenotypes (BPT/RT) } \\
\hline Common & $\begin{array}{l}\text { Number of } \\
\text { strains }\end{array}$ & Single $†$ \\
\hline $\mathrm{Al} / 385$ & 3 & $\mathrm{~A} 1 / 380$ \\
\hline $\mathrm{Al} / 65$ & 3 & $\mathrm{~A} 2 / 20$ \\
\hline $\mathrm{A} 4 / 380$ & 2 & $\begin{array}{l}\text { A3/385 } \\
\text { A5/0 }\end{array}$ \\
\hline B1 $/ 387$ & 4 & B1 / 357 \\
\hline B1 $/ 385$ & 4 & B1/265 \\
\hline $\mathrm{B} 1 / 367$ & 2 & B1 $/ 255$ \\
\hline $\mathrm{B1} / 365$ & 6 & $\mathrm{~B} 2 / 0^{*}$ \\
\hline $\mathrm{B} 1 / 355$ & 3 & \\
\hline B1 $/ 167$ & 2 & B3 $/ 0^{*}$ \\
\hline $\mathrm{B} 1 / 0$ & $9^{*}$ & B4/387 \\
\hline $\mathrm{B} 6 / 387$ & 7 & B $5 / 0^{*}$ \\
\hline $\mathrm{B} 6 / 385$ & 5 & B6 $/ 377$ \\
\hline \multirow[t]{6}{*}{ B $7 / 0$} & $2^{*}$ & B6 $/ 365$ \\
\hline & & B6/185 \\
\hline & & $\mathrm{Cl} / 375$ \\
\hline & & C $2 / 385$ \\
\hline & & $\mathrm{D} 1 / 0$ \\
\hline & & $\mathrm{El} / 0^{*}$ \\
\hline
\end{tabular}

* Of 70 strains tested, 15 were isolated in countries other than Iran.

†These BPT/RT phenotypes were represented by only one strain each. source of carbon was an important character in tracing the origin of Havana strains. With the $\mathrm{PhP}$ system and a different set of reactions for subtyping of Typhimurium strains (PhP-ST), isolated from cases of human gastroenteritis in Iran, we have found similar results (unpublished observations).

Biotyping, if sufficiently discriminatory, has been suggested as the most suitable typing method to identify the source of infection by salmonella serotypes for which phage typing, plasmid analysis, or other typing methods are not available or cannot be applied. ${ }^{31}$

Although antimicrobial-susceptibility testing together with virulence properties sufficiently identified the presence of major epidemic clones among Iranian isolates, they failed to differentiate non-Iranian isolates, because the latter strains did not carry resistance genes. In contrast, a good discrimination was achieved by biochemical fingerprinting implying that this method can also be used alone to highlight major epidemic strains of Salmonella Havana present in a community or a country.

In comparison with conventional biotyping systems in which the results of biochemical tests are based on absolute "positive" or "negative" values, the computerised biochemical-fingerprinting method described here measures the kinetics of the bacterial metabolism of different substrates and the results are expressed quantitatively after several readings. Thus, the risk of false-positive or -negative interpretation is eliminated. Furthermore, the $\mathrm{PhP}$ system is easy to perform and a large number of strains may be tested within a relatively short period. Moreover, whereas other typing methods show only identity or nonidentity among tested strains, numerical analysis, as used in the PhP system, also shows relationships

Table III. Strains of Salmonella of serotype Havana grouped on the basis of biochemical phenotype (BPT) and virulence properties

\begin{tabular}{|c|c|c|c|c|c|c|}
\hline \multicolumn{4}{|c|}{ Common phenotypes } & \multicolumn{3}{|c|}{ Single phenotypes } \\
\hline BPT & $\begin{array}{l}\text { HeLa cell } \\
\text { adherence }\end{array}$ & $\begin{array}{l}\text { Aerobactin } \\
\text { production }\end{array}$ & $\begin{array}{c}\text { Number of } \\
\text { strains }\end{array}$ & BPT & $\begin{array}{l}\text { HeLa cell } \\
\text { adherence }\end{array}$ & $\begin{array}{l}\text { Aerobactin } \\
\text { production }\end{array}$ \\
\hline Al & $\mathrm{L}$ & - & 5 & $\mathrm{Al}$ & $L / D$ & - \\
\hline \multirow{4}{*}{ A4 } & D & - & 2 & A1 & - & - \\
\hline & & & & A2 & - & - \\
\hline & & & & A3 & $\mathrm{L}$ & - \\
\hline & & & & A5 & L/D & - \\
\hline B1 & L & + & 5 & B2* & - & - \\
\hline B1 & L & - & 13 & B3* & - & - \\
\hline B1 & - & + & 4 & B4 & - & - \\
\hline B1 & - & - & $11\left(9^{*}\right)$ & B5* & - & - \\
\hline B6 & L & + & 13 & & & \\
\hline B6 & - & + & 2 & & & \\
\hline \multirow[t]{5}{*}{ B7 } & - & - & $2^{*}$ & & & \\
\hline & & & & $\mathrm{Cl}$ & L & - \\
\hline & & & & C2 & $\mathbf{L}$ & - \\
\hline & & & & D1 & - & - \\
\hline & & & & $\mathrm{El}^{*}$ & - & - \\
\hline
\end{tabular}

*Of 70 strains tested, 15 were isolated in countries other than Iran. Adherence to HeLa cells was: $L$, localised; $D$, diffuse : $L / D$, both $L$ and $D$ in same preparation. 


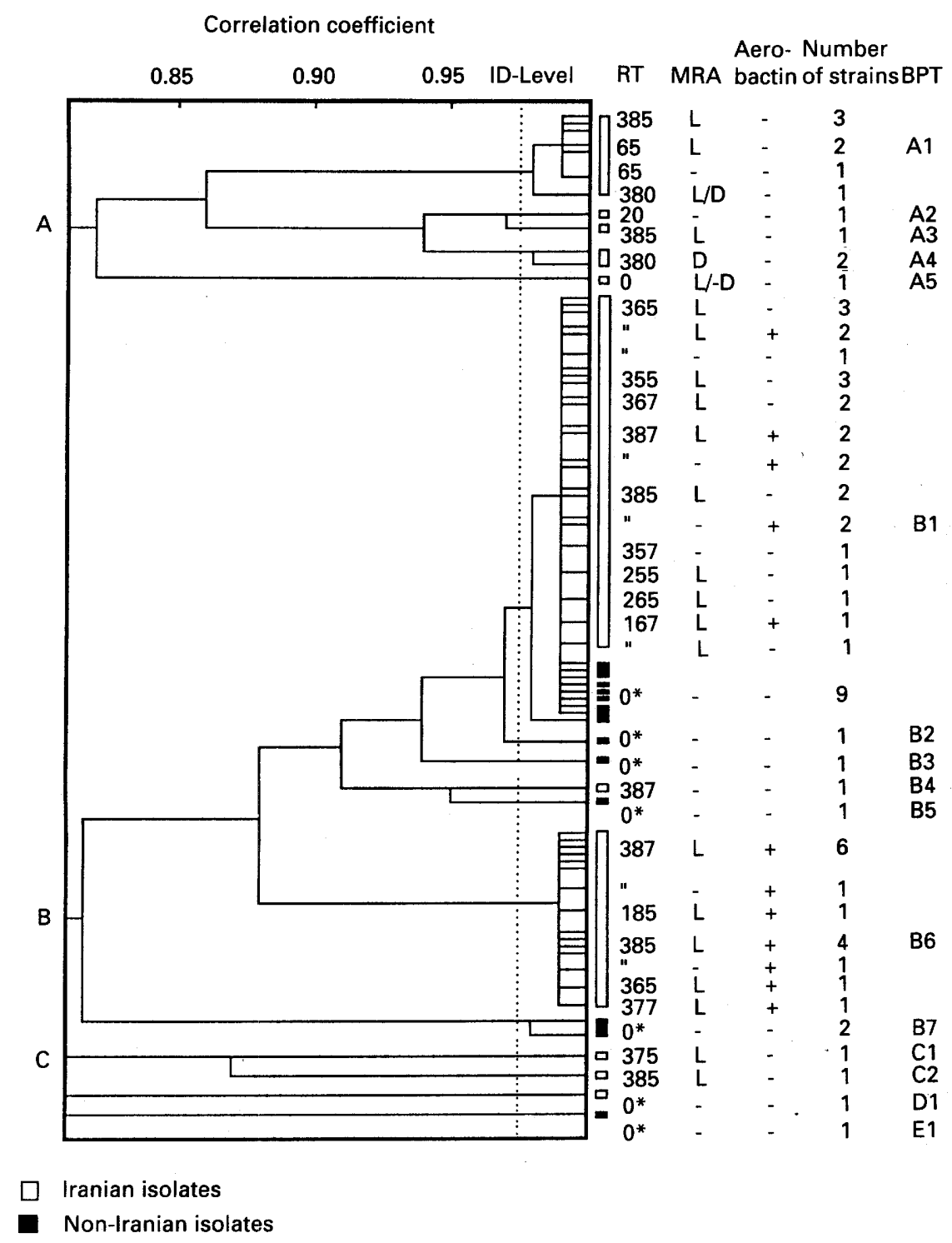

Fig. 2. Clonal groups of Havana strains isolated in Iran (55) and in other countries* (15) based on BPTs, RT and virulence properties. IDlevel indicates the chosen identity level $(r=0.980)$ for strains assigned to the same BPT. MRA, mannose-resistant adhesion to HeLa cells; $\mathrm{L}$, localised adhesion; D, diffuse adhesion; L/D, both localised and diffuse adhesion in same preparation.

among non-identical isolates in the form of a dendrogram. This information may help trace phenotypic variations occurring within bacterial clones.

In epidemiological studies, where a single clone is almost certainly responsible for all cases of disease, it may be important to distinguish the outbreak strains from the large background of endemic and nonendemic strains. The achievement of this goal depends on many factors including genetic stability of the organism, the selective pressure of the environment and the discriminatory power of the given procedure. ${ }^{29}$ Since the stability of many microbial traits which are coded by plasmids is influenced by environmental selective pressure, it has been suggested that determination of clonality by phenotypic analysis should be performed by a combination of techniques. ${ }^{24,32}$ Virulence properties of bacteria, as used in this study, together with biochemical fingerprinting made an ideal combination to identify major epidemic clones of
Havana strains in Iran and may be used in future studies to differentiate epidemic strains of Havana from endemic and non-endemic strains in this country.

In conclusion, we found that four different BPTs of Havana strains are common in Iran, but two, probably related BPTs are particularly responsible for the majority of Havana infection there. However, the BPT most frequently found among these isolates was also common among Havana strains from other countries. The biochemical fingerprinting with the $\mathrm{PhP}$ system sufficiently identified the presence of different clones among the population tested. The method is reproducible, easy to perform and can be used alone, or in combination with other methods in epidemiological studies of Havana strains.

We thank Ms Gunnel Sigstam and Ms Birgitta Karlsson for their skilful technical assistance. This study was supported by the Swedish Board for Agricultural and Forestry Research grants 0564/89 L 139 and $0777 / 89 \mathrm{D} \mathrm{326}$, and by the Karolinska Institute fund. 


\section{References}

1. Corbelo A, Martinez-Cruz JA. Historia de la Salmonella havana. Arch de Med Infect 1941; 10: 170-179.

2. Pavia AT, Shipman LD, Wells JG et al. Epidemiologic evidence that prior antimicrobial exposure decreases resistance to infection by antimicrobial-sensitive Salmonella. $J$ Infect Dis 1990; 161 : 255-260.

3. Fule RP, Saoji AM. Isolation of Salmonella havana (13, 23 :f.g:-) a rare serotype from human source. Indian $J$ Pathol Microbiol 1988; $31: 67-68$.

4. Soerjadi-Liem AS, Cumming RB. Studies on the incidence of Salmonella carriers in broiler flocks entering a poultry processing plant in Australia. Poultry Science 1984; 63: 892-895.

5. Bensink JC. Salmonella contamination of meat and bone meal. Aust Vet J 1979; 55: 13-15.

6. Yoshimura $\mathrm{H}$, Nakamura $\mathrm{H}$, Sato $\mathrm{S}$. Incidence of salmonellae in animal feed ingredients in Japan. Natl Inst Anim Health $Q 1979 ; 19: 107-113$.

7. Berchieri A, Irino $\mathrm{K}$, Neme $\mathrm{SN}$ et al. Contaminacao por Salmonella em farinhas de origem animal utilizados no preparo de racao. Pesquisa Veterinaria Brasileira 1984; 4 : 83-88.

8. Farhoudi-Moghaddam AA, Katouli M, Jafari A, Bahavar MA, Parsi M, Malekzadeh F. Antimicrobial drug resistance and resistance factor transfer among clinical isolates of salmonellae in Iran. Scand J Infect Dis 1990; 22: 197-203.

9. Anderson ES, Ward LR, de Saxe MJ, de Sa JDH. Bacteriophage-typing designations of Salmonella typhimurium. $J$ Hyg 1977; 78 : 297-300.

10. Duguid JP, Anderson ES, Alfredsson GA, Barker R, Old DC. A new biotyping scheme for Salmonella typhimurium and its phylogenetic significance. $J$ Med Microbiol 1975; 8, 149-166.

11. Barker RM, Keaerney GM, Nicholson P, Blair AL, Porter RC, Crichton PB. Types of Salmonella paratyphi B and their phylogenetic significance. J Med Microbiol 1988; 26: 285-293.

12. Brunner F, Margadant A, Peduzzi R, Piffaretti J-C. The plasmid pattern as an epidemiologic tool for Salmonella typhimurium epidemics: comparison with the lysotype. $J$ Infect Dis 1983; 148: 7-11.

13. Threlfall EJ, Frost JA. The identification, typing and fingerprinting of Salmonella: laboratory aspects and epidemiological applications. $J$ Appl Bacteriol 1990; 68: 5-16.

14. Mitchell E, O'Mahoney M, Lynch D et al. Large outbreak of food poisoning caused by Salmonella typhimurium definitive type 49 in mayonnaise. $B r$ Med $J$ 1989; 298: 99-101

15. Riley LW, DiFerdinando GT, DeMelf TM, Cohen ML Evaluation of isolated cases of salmonellosis by plasmid profile analysis: introduction and transmission of bacterial clone by precooked roast beef. $J$ Infect Dis 1983; 148: $12-17$.

16. Taylor DN, Wachsmuth IK, Shangkuan Y-H et al. Salmonellosis associated with marijuana. A multistate outbreak traced by plasmid fingerprinting. $N$ Engl J Med $1982 ; 306$ : 1249-1253.

17. Kühn I. Biochemical fingerprinting of Escherichia coli: a simple method for epidemiological investigations. $J$ Microbiol Methods 1985; 3: 159-170.

18. Kühn I, Burman LG, Eriksson L, Möllby R. Subtyping of Klebsiella by biochemical fingerprinting: a simple system for epidemiological investigations. J Microbiol Methods 1990; 11: 177-185.

19. Bauer AW, Kirby WMM, Sherris JC, Turck M. Antibiotic susceptibility testing by a standardized single disk method. Am J Clin Pathol 1966; 45: 493-496.

20. Sneath PHA, Sokal RR. Numerical taxonomy. San Francisco, CA, WH Freeman. 1973.

21. Cravioto A, Gross RJ, Scotland SM, Rowe B. Adhesive factor found in strains of Escherichia coli belonging to the traditional infantile enteropathogenic serotypes. Curr Microbiol 1979; 3: 95-99.

22. Scaletsky ICA, Silva MLM, Trabulsi LR. Distinctive pattern of adherence of enteropathogenic Escherichia coli to HeLa cells. Infect Immun 1984; 45: 534-536.

23. Roberts RB, Abelson PH, Cowe DB, Bolton ET, Britten RJ. Studies of biosynthesis in Escherichia coli. Publication 607, Carnegie Institute of Washington DC. 1955.

24. McDonough PL, Timoney JF, Jacobson RH, Khakhria R. Clonal groups of Salmonella typhimurium in New York State. J Clin Microbiol 1989; 27: 622-627.

25. Holmberg SD, Wachsmuth IK, Hickman-Brenner FW, Cohen ML. Comparison of plasmid profile analysis, phage typing, and antimicrobial susceptibility testing in characterizing Salmonella typhimurium isolates from outbreaks. J Clin Microbiol 1984; 19: 100-104.

26. Anderson ES. The modern ecological study of Salmonella typhimurium infection. In: Perez-Miravete A, Peleaz (eds) Recent advances in microbiology. Proceedings of the Xth International Congress for Microbiology, Mexico City. 1970: 381 .

27. Crichton PB, Old DC. A biotyping scheme for the subspecific discrimination of Escherichia coli. J Med Microbiol 1982; 15: $233-242$

28. Simoons-Smit AM, Verweij-van Vught AMJJ, Kanis IYR, MacLaren DM. Biochemical and serological investigations on clinical isolates of Klebsiella. J Hyg 1985; 95: 265-276.

29. Eisenstein BI. New molecular techniques for microbial epidemiology and the diagnosis of infectious diseases. J Infect Dis 1990 ; 161 : $595-602$.

30. Katouli M, Kühn I, Möllby R. Evaluation of the stability of biochemical phenotypes of Escherichia coli upon subculturing and storage. $J$ Gen Microbiol 1990; 136: 16811688

31. Barker RM, Old DC. The usefulness of biotyping in studying the epidemiology and phylogeny of salmonellae. $J$ Med Microbiol 1989; 29: 81-88.

32. Barker R, Old DC, Sharp JCM. Phage type/biotype groups of Salmonella typhimurium in Scotland 1974-6: variation during spread of epidemic clones. J Hyg 1980; 84: 115-125. 